\title{
SIMULASI PERUBAHAN ENERGI PER BIT DAN DERAU TERHADAP JUMLAH KANAL DAN CAKUPAN WCDMA
}

\author{
Alfin Hikmaturokhman ${ }^{1}$, Hesti Susilawati ${ }^{2}$, Tantiningrum Niken ${ }^{1}$ \\ ${ }^{1}$ Akademi Teknik Telkom Sandhy Putra Purwokerto \\ ${ }^{1}$ JI DI Panjaitan No 128 Purwokerto, (0281) 641629, (0281) 641630 \\ ${ }^{2}$ Program Sarjana Teknik Unsoed Purwokerto \\ ${ }^{2}$ Jl. Kampus No.1, Grendeng, Purwokerto, 53122 (0281) 630696, (0281) 630696 \\ e-mail: alfin_h21@yahoo.com ${ }^{1}$, hesti_s@yahoo.co.id ${ }^{2}$
}

\begin{abstract}
$E_{b} / N_{o}$ parameter is the measure of signal to noise ratio for a digital communication system, it is measured at the input to the receiver and is used as the basic measure of how strong the signal is, or in other words $E_{b} / N_{o}$ indicates the fluctuation of received signal strength in the receiver. $E_{b} / N_{o}$ is affected by several factors, such as speed of mobile station, propagation environment and bit rate. The variations of $E_{b} / N_{o}$ value will affect to the number of offered channel and coverage in WCDMA. The impact of the variation of $E_{b} / N_{o}$ value could be recognized in the result of the calculations. The purpose of this research is to build simulation models by using Delphi to view and analyze the influence of $E_{b} / N_{o}$ of total channels and WCDMA coverage. The results from simulation analysis showed that the larger of $E_{b} / N_{o}$ and bit rate used, the number of channels on offer will be smaller and the value of BS is low sensitivity, which means loads of traffic will also offer little that would cause the quality to be better systems and transmit power $M S$ becomes more lower in order to maintain the value of $E_{b} / N_{o}$ to avoid the drop call.
\end{abstract}

Keywords: WCDMA, $E_{b} / N_{o}$ signal to derau ratio, coverage, bit rate

\begin{abstract}
Abstrak
Parameter $E_{b} / N_{o}$ adalah rasio perbandingan energy bit terhadap derau untuk sistem komunikasi digital dan digunakan sebagai ukuran untuk mengukur seberapa kuat sinyal yang diterima oleh penerima, atau dengan kata lain $E_{b} / N_{o}$ merupakan indikasi dari lemahnya sinyal yang diterima yang bisa dideteksi oleh penerima di atas suatu harga level derau yang sudah ditetapkan. Parameter $E_{b} / N_{o}$ merupakan parameter dimana nilainya mempengaruhi jumlah kanal dan cakupan WCDMA. $E_{b} / N_{o}$ akan banyak dipengaruhi oleh beberapa faktor diantaranya adalah kecepatan pergerakan, lingkungan propagasi, dan bit rate yang digunakan. Tujuan penelitian ini adalah membangun model simulasi menggunakan Delphi untuk melihat dan menganalisis pengaruh $E_{b} / N_{o}$ terhadap Jumlah Kanal dan Cakupan WCDMA. Hasil analisis dari simulasi menunjukan bahwa semakin besar nilai $E_{b} / N_{o}$ dan bit rate yang digunakan, maka jumlah kanal yang ditawarkan akan semakin kecil dan nilai sensitivitas $B S$ menjadi rendah, artinya beban trafik yang ditawarkan juga akan semakin kecil sehingga akan mengakibatkan kualitas sistem menjadi lebih baik dan daya pancar MS menjadi lebih. rendah dalam rangka untuk mempertahankan nilai $E_{b} / N_{o}$ agar tidak terjadi drop call.
\end{abstract}

Kata kunci: WCDMA, $E_{b} / N_{o}$, signal to derau ratio, cakupan, bit rate

\section{PENDAHULUAN}

\section{Wideband CDMA (WCDMA)}

adalah standar 3G yang menggunakan salah satu saluran $5 \mathrm{MHz}$ untuk suara dan data, dan menawarkan kecepatan hingga 2 Mbps. Tingginya bit rate yang ditawarkan tentu saja akan mempengaruhi kapasitas trafik dan cakupan area pada sel tersebut [1] . Parameter penting yang digunakan untuk menghitung kapasitas trafik dan radius cakupan suatu sel adalah parameter energy bit terhadap derau $\left(E_{b} / N_{o}\right)$ yang digunakan untuk mengukur kualitas sambungan pada sistem seluler WCDMA. Karena itu, 
perubahan nilai $E_{b} / N_{o}$ sangat berpengaruh terhadap perubahan jumlah kanal dan cakupan area WCDMA [2].

Dalam perhitungan kapasitas trafik WCDMA, parameter $E_{b} / N_{o}$ digunakan untuk menentukan jumlah kanal yang ditawarkan. Sedangkan dalam perhitungan cakupan, parameter $E_{b} / N_{o}$ sangat penting untuk menentukan apakah user tersebut dapat dilayani atau tidak oleh Base Station (BS) pada sel tunggal tersebut. Pada [3] belum diteliti adanya perbedaan $E_{b} / N_{o}$ yang akan mempengaruhi kualitas sistem dan daya pancar Mobile Station (MS) yang akhirnya akan mempengaruhi hasil dari penelitian tersebut. Pada penelitian ini kami mengembangkan simulasi menggunakan Bahasa Pemrograman Delphi untuk menganalisis adanya perbedaan $E_{b} / N_{o}$ yang akan mempengaruhi jumlah kanal dan cakupan WCDMA..

Pada makalah ini diasumsikan sel tunggal tidak dipengaruhi oleh interferensi sel di sekitarnya dan interferensi antar user pada sel tersebut diabaikan. Parameter $E_{b} / N_{o}$ dipengaruhi oleh beberapa faktor, diantaranya adalah bit rate yang digunakan. Oleh karena itu, diberikan dua nilai bit rate yang berbeda yaitu 9600 bps dan 14400 bps untuk memperjelas pengaruh dari bit rate yang digunakan. Nilai chip rate yang digunakan pada standar WCDMA sesuai 3GPP adalah sebesar 3,84 Mcps .

\section{METODE PENELITIAN}

Penelitian yang dilakukan dengan cara membangun simulasi dengan menggunakan Bahasa Pemrograman Delphi untuk menganalisis pengaruh perbedaan $\mathrm{E}_{\mathrm{b}} / \mathrm{N}_{\mathrm{o}}$ terhadap Jumlah Kanal dan Cakupan WCDMA. Program simulasi yang akan digunakan untuk membantu perhitungan, dapat dilihat pada diagram alir berikut:

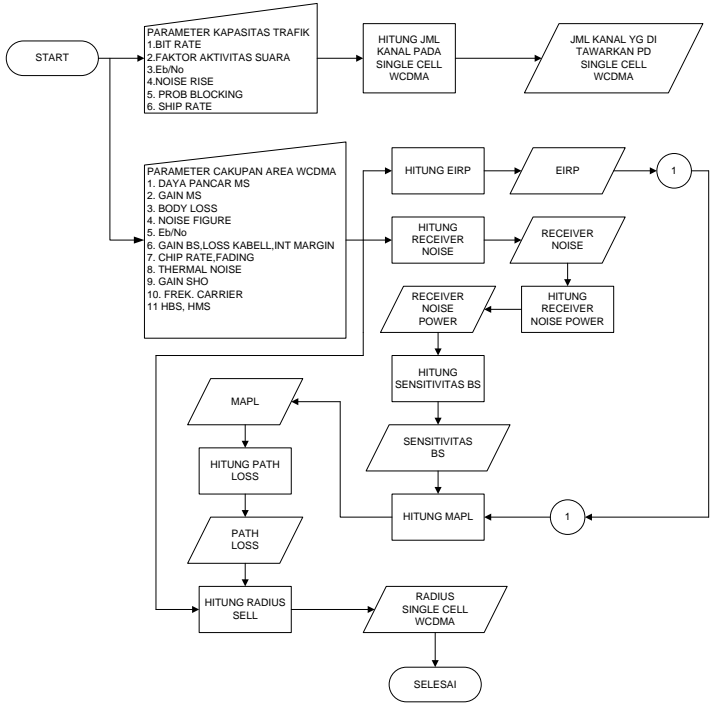

Gambar 1. Diagram alir simulasi menggunakan Delphi untuk melihat dan menganalisis pengaruh $\mathrm{E}_{\mathrm{b}} / \mathrm{N}_{\mathrm{o}}$ terhadap Jumlah Kanal dan Cakupan WCDMA

Parameter-parameter yang diperhitungkan dalam kapasitas trafik dan penentuan radius cakupannya tersebut adalah sebagai berikut:

\subsection{Morfologi Area Perencanaan}

Sebelum menentukan dimana BS nantinya akan ditempatkan, maka perlu diketahui jenis area dan padatnya penduduk pada area tersebut. Model Okumura membagi 3 jenis area yang berbeda, yaitu[5]:

1) Area Urban

2) Area Suburban 
3) Area Terbuka (Open Area)

\subsection{Propagasi Outdoor COST 231}

Model propagasi berdasarkan lingkungan outdoor dan indoor. Adanya pemantulan dari beberapa objek dan pergerakan MS akan menyebabkan kuat sinyal yang diterima oleh MS bervariasi, dari sinyal yang diterima tersebut akan mengalami pathloss, dimana akan membatasi kinerja dari sistem komunikasi bergerak. Model propagasi memprediksikan rata-rata kuat sinyal yang diterima oleh MS pada jarak tertentu dari BS ke MS,selain itu digunakan memperkirakan daerah cakupan BS sehingga ukuran sel dari BS dapat ditentukan. Model propagasi juga digunakan menentukan daya maksimum yang dapat dipancarkan untuk menghasilkan kualitas pelayanan yang sama pada frekuensi yang berbeda[5].

Model ekstensi COST 231 merupakan pengembangan dari model Hata untuk sistem di daerah urban dengan rentang frekuensi antara $1,5 \mathrm{GHz}$ hingga 2 $\mathrm{GHz}$ yang diajukan pertama kali oleh The European Co-operative for Scientific and Technical research (EURO-COST). Formula standar dari model ini adalah EUR91[4]:

$\operatorname{PL}(d B)=46,3+33,9 \log f \mathrm{c}-13,82 \log$ hte $\mathrm{a}(\mathrm{hre})+(44,9-$ 6,55loghte $) \log d+\mathrm{CM}$

Sedangkan nilai a(hre) COST 231 dihitung menggunakan rumus: $a(h r e)=(1,1 \log (f c)-0,7)$ hre $-(1,56 \log (f c)-0,8)$

dimana:

$\mathrm{f}_{\mathrm{c}}=$ frekuensi $1500 \mathrm{MHz}-2000 \mathrm{MHz}$

$\mathrm{h}_{\mathrm{te}}=$ tinggi antena BS $30 \mathrm{~m}-200 \mathrm{~m}$

$\mathrm{h}_{\mathrm{re}}=$ tinggi antena MS $1 \mathrm{~m}-10 \mathrm{~m}$

$\mathrm{d}=$ jarak pemancar dan penerima 1

$\mathrm{km}$ sampai $20 \mathrm{~km}$

$\mathrm{a}\left(\mathrm{h}_{\mathrm{re}}\right)=$ faktor koreksi untuk tinggi efektif antena MS

$\mathrm{C}_{\mathrm{M}}$ = faktor koreksi untuk ukuran kota

Nilai $\mathrm{C}_{\mathrm{M}}=0 \mathrm{~dB}$ untuk ukuran medium small city

Nilai $\mathrm{C}_{\mathrm{M}}=3 \mathrm{~dB}$ untuk daerah pusat kota (metropolitan/large city)

Daerah suburban:

$P L(d B)=P L($ urban $)-2[\log (\mathrm{fc} / 28)]^{2}-5,4$

\subsection{Pengaruh Perubahan $E_{b} / N_{o}$ terhadap \\ Jumlah Kanal yang Ditawarkan}

Untuk memaksimalkan kapasitas dari sistem, maka salah satu caranya adalah dengan membatasi level transmit dari masing-masing user sehingga bisa mengurangi interferensi total pada sistem, atau dengan kata lain perubahan level power transmit dari masing-masing user juga akan membawa perubahan pada kapasitas sistem.

Parameter $E_{b} / N_{o}$ adalah rasio perbandingan pengukuran sinyal terhadap derau untuk sistem komunikasi digital dan digunakan sebagai ukuran untuk menglikur seberapa kuat sinyal yang diterima oleh penerima, atau dengan kata lain $E_{b} / N_{o}$ 
merupakan indikasi dari lemahnya sinyal yang diterima yang bisa dideteksi oleh receiver diatas suatu harga level derau yang sudah ditetapkan [5].

$$
\frac{E b}{N_{0}}=\frac{P}{(I-P)} \frac{W}{R}
$$

dimana:

$$
\begin{aligned}
\mathrm{P} & =\text { daya sinyal informasi yang } \\
& \text { diterima dari MS pada antena } \mathrm{BS} \\
& \text { (Watt) } \\
\mathrm{R} & =\text { data rate ( } 9600 \text { bps untuk bit rate } \\
& 1 \text {, dan } 14400 \text { bps untuk bit rate } 2) \\
\mathrm{W} & =\text { chip rate (Mcps) } \\
\mathrm{I} & =\text { total interferensi (Watt) }
\end{aligned}
$$

$E_{b} / N_{o}$ minimum perlu ditentukan untuk mendapatkan performansi sistem yang memadai. Pada artikel jurnal, range nilai $E_{b} / N_{o}$ diasumsikan sebesar $5 \mathrm{~dB}$ hingga 7 $\mathrm{dB}$.

Pada perhitungan kapasitas trafik, untuk mengetahui jumlah kanal yang ditawarkan pada sel tunggal WCDMA, harus terlebih dahulu dihitung parameter Noise_Rise dengan nilai $\eta_{u l}$ (Uplink Load Factor) yang diasumsikan sebesar 50\%, menggunakan persamaan adalah sebagai berikut

$$
\text { Noise_Rise }=-\left(10 \log \left(1-\eta_{u l}\right)\right)
$$

Jumlah kanal yang ditawarkan dimana interferensi antar sel tetangga diperhitungkan, dapat hitung dengan persamaan sebagai berikut:

$$
N=\left(1-\frac{1}{\text { Noise_Rise }}\right) \frac{1}{(1+i)}\left(1+\frac{W}{\frac{E b}{N_{o}} R k} v\right)_{(4)}
$$

Interferensi antar sel tetangga (intercell interference) diabaikan maka perhitungan (sel tunggal), dapat dihitung dengan persamaan sebagai berikut

$$
N_{s o f t}=\left(1-\frac{1}{\text { Noise_Rise }}\right)\left(1+\frac{W}{\frac{E_{b}}{N_{o}} R_{k}} v\right)
$$

dimana:

$$
\begin{aligned}
\mathrm{N}_{\text {soft }} & =\text { jumlah kanal per sel } \\
W & =\text { WCDMA chip rate }(3.84 \mathrm{Mcps}) \\
R_{k} & =\text { Bit rate user }(\mathrm{bps}) \\
v & =\text { faktor aktivitas suara }(\%) \\
\frac{E_{b}}{N_{o}} & =\text { Energy bit per Derau }(\mathrm{dB})
\end{aligned}
$$

Besarnya beban trafik yang ditawarkan dapat diketahui dengan menggunakan Tabel Erlang dengan probabilitas Blocking atau Grade of Service (GOS) sebesar 2\%. Artinya setiap 100 pelanggan yang melakukan panggilan, 2 pelanggan diantaranya ditolak[6]:

$$
\boldsymbol{B}\left(\boldsymbol{N}_{s}, \boldsymbol{\rho}_{s}\right)=2 \%
$$

dimana:

$$
\begin{aligned}
\mathrm{N}_{\mathrm{s}} & =\text { jumlah kanal } \\
\rho_{s} & =\text { offered load untuk sel tunggal }
\end{aligned}
$$

\subsection{Pengaruh Perubahan $E_{b} / N_{o}$ terhadap Cakupan WCDMA}


Perhitungan radius atau cakupan sel, dimulai dengan perhitungan dari sisi uplink, penyebabnya karena besar kecilnya daya yang ditransmisikan oleh $B S$ dari $M S$ (efek jauh dekat). Oleh karena itu, pembahasan dalam artikel jurnal ini mencakup perencanaan cakupan dan kapasitas trafik pada sisi uplink. Pengontrolan daya yang baik dari sisi BS dan MS, akan menyebabkan kualitas sinyal dapat dijaga tetap baik, dan efek interferensi yang terjadi dapat dikurangi. Parameter yang digunakan dalam perhitungan radius cakupan mencakup link budget sisi uplink dan sisi downlink[6].

Kondisi area urban, suburban ataupun open area memiliki persamaan yang berbeda pada perhitungan model propagasi. Model propagasi diperlukan untuk menentukan berapa jumlah sel yang diperlukan untuk melayani suatu area pelayanan. Apabila digunakan bit rate yang berbeda, maka akan mempengaruhi nilai Processing Gain. Persamaan untuk menghitung Processing Gain adalah sebagai berikut :

$\mathrm{Gp}=10 \quad \log \quad(\mathrm{W} / \mathrm{R})$ (9)

dimana:

$$
\begin{aligned}
& \mathrm{W}=\text { chip rate yang digunakan (Mcps) } \\
& \mathrm{R}=\text { bit rate yang digunakan }(9600 \mathrm{bps} \\
& \text { dan } 14400 \mathrm{bps})
\end{aligned}
$$

Parameter $E_{b} / N_{o}$ pada perhitungan cakupan mempengaruhi nilai sensitivitas
BS, untuk menentukan apakah user tersebut dapat dilayani atau tidak oleh BS.

Sensitivitas BS =Eb/No-W/R + Im Receiver Noise Power

dimana:

Sens BS = level daya terima minimum yang diperlukan BS untuk memperoleh nilai $\mathrm{Eb} / \mathrm{N}_{0}$ yang diinginkan, agar user dapat tetap melakukan hubungan $(\mathrm{dBm})$

$\mathrm{Eb} / \mathrm{N}_{0}=$ energi bit per Derau $(5 \mathrm{~dB}-7 \mathrm{~dB})$

$W / R \quad=$ Processing Gain $(\mathrm{dB})$

$\mathrm{I}_{\mathrm{m}} \quad=$ Margin Interference $(\mathrm{dBm})$

Derau Power $=$ penjumlahan antara Receiver Derau dengan chip rate yang digunakan $(\mathrm{dBm})$

Dalam artikel jurnal, kondisi area yang ditentukan adalah urban dan suburban. Persamaannya adalah sebagai berikut[4]:

Untuk daerah urban:

$$
R=\exp \left(\frac{(P L-(46,3+33,9 \log f c-13,82 \log h t e-a(h r e)+C M))}{(44,9-6,55 \log h t e)}\right)
$$

Untuk daerah suburban:
$R=\exp \left(\frac{\left(P L-\left(46,3+33,9 \log f c-13,82 \log h t e-a(h r e)+C M-2(\log (f c / 28))^{2}-5,4\right.\right.}{(44,9-6,55 \log (h t e))}\right)$

\section{ANALISA DAN PEMBAHASAN}

Dari hasil model simulasi menggunakan Delphi yang telah dibuat maka dapat dianalisis sebagai berikut 
3.1 Pengaruh Perubahan $E_{b} / N_{o}$ terhadap

Jumlah Kanal yang Ditawarkan

Kapasitas trafik pada sel tunggal WCDMA dapat diketahui dari jumlah kanal yang ditawarkan pada sel tersebut. Untuk dapat menghitung jumlah kanal yang ditawarkan pada sel tunggal, maka dapat dimulai dari perhitungan Derau Rise.

a. Perhitungan Derau Rise

Kapasitas suatu sel bertambah maka interferensi juga akan bertambah.

Persamaan (5) digunakan untuk menghitung Derau Rise dengan Uplink Load factor yang diasumsikan sebesar 50\%,sehingga akan didapat Derau Rise sebesar $3 \mathrm{~dB}$

b. Perhitungan Jumlah kanal sel tunggal WCDMA

Jumlah kanal yang dihitung pada sel tunggal WCDMA menggunakan persamaan (7),sehingga untuk bit rate 1 = 9600 bps dengan nilai $E_{b} / N_{o}=5 \mathrm{~dB}$, maka didapat jumlah kanal yang ditawarkan pada sel tunggal WCDMA sebesar 42 kanal.

Dengan nilai $E_{b} / N_{o}=6 \mathrm{~dB}$, maka didapat jumlah kanal yang ditawarkan adalah 34 kanal. Sedangkan bila nilai $E_{b} / N_{o}=7 \mathrm{~dB}$, maka jumlah kanal yang ditawarkan menjadi lebih kecil nilainya yaitu hanya sebesar 27 kanal,namun, jika bit rate yang digunakan sebesar $14400 \mathrm{bps}$, terdapat perubahan jumlah kanal yang ditawarkan pada sel tunggal tersebut.
Untuk nilai $E_{b} / N_{o}=5 \mathrm{~dB}$, maka jumlah kanal yang didapat adalah sebesar 28 kanal. Nilai $E_{b} / N_{o}=6 \mathrm{~dB}$, jumlah kanal yang ditawarkan sebesar 22 kanal. Sedangkan pada saat nilai $E_{b} / N_{o}=7 \mathrm{~dB}$, jumlah kanal yang ditawarkan hanya 18 kanal.

Semakin besar nilai $E_{b} / N_{o}$ maka jumlah kanal yang ditawarkan pada sel tunggal WCDMA akan semakin kecil atau dengan kata lain, semakin besar nilai $E_{b} / N_{o}$ maka semakin sedikit pula user yang dapat ditampung pada sel tersebut. Jika dilihat dari bit rate yang ditawarkan, semakin tinggi bit rate yang digunakan maka jumlah kanal yang ditawarkan juga akan semakin kecil.

Perubahan $E_{b} / N_{o} \quad$ berpengaruh terhadap jumlah kanal yang ditawarkan yang dapat dilihat pada gambar 1 yang merupakan gambar hasil dari simulasi perhitungan diatas:

Garis diatas pada grafik menunjukkan hubungan $E_{b} / N_{o}$ terhadap jumlah kanal yang ditawarkan untuk bit rate 9600 bps. Sedangkan Garis dibawah pada grafik menunjukkan hubungan $E_{b} / N_{o}$ terhadap jumlah kanal yang ditawarkan untuk bit rate 14400 bps.

Semakin rendah bit rate yang digunakan, maka jumlah kanal yang ditawarkan pada sel tunggal WCDMA akan semakin banyak. Semakin besar 
jumlah kanal maka semakin besar pula beban kapasitas trafik yang ditawarkan, begitu juga sebaliknya. Semakin kecil beban kapasitas trafik yang ditawarkan, maka kualitas sistem akan semakin bagus.

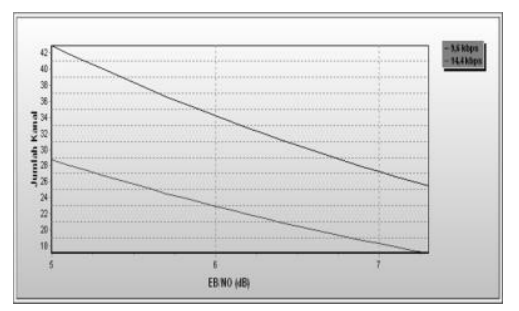

Gambar 2. Grafik hubungan antara nilai $E_{b} / N_{o}$ dengan jumlah kanal yang ditawarkan

\subsection{Pengaruh Perubahan $E_{b} / N_{o}$ terhadap Cakupan WCDMA}

Perhitungan radius atau range sel, dimulai dengan perhitungan dari sisi uplink, hal ini dikarenakan besar kecilnya daya yang ditransmisikan oleh $B S$ dari $M S$ (efek jauh dekat). Oleh karena itu, pembahasan dalam artikel jurnal ini mencakup perencanaan cakupan dan kapasitas trafik pada sisi uplink.

Perubahan parameter $\mathrm{Eb} / \mathrm{N}_{0}$ yang mempunyai range nilai dari $5 \mathrm{~dB}$ hingga 7 dB mempengaruhi nilai Sensitivitas BS. Pada artikel jurnal ini digunakan bit rate 9600 bps dan 14400 bps.

Perhitungan bit rate 9600 bps, didapatkan Processing Gain dengan persamaan (9), sebesar 26,02 dB,sedangkan untuk bit rate 14400 bps, didapatkan Processing Gain sebesar 24,26 dB.

Perbedaan bit rate yang digunakan mempengaruhi nilai Processing Gain juga akan mempengaruhi nilai sensitivitas BS dan secara otomatis akan mempengaruhi radius cakupan sel tunggal WCDMA.

Untuk bit rate 9600 bps dimana nilai $E_{b} / N_{o}=5 \mathrm{~dB}$, sensitivitas $\mathrm{BS}$ yang didapat adalah sebesar $-121,2 \mathrm{dBm}$, nilai $E_{b} / N_{o}=6 \mathrm{~dB}$, sensitivitas $\mathrm{BS}$ adalah sebesar $-120,2 \mathrm{dBm}$, sedangkan nilai $E_{b} / N_{o}=7 \mathrm{~dB}$, sensitivitas BS adalah sebesar -119,2 dBm.

Untuk bit rate 14400 bps dimana nilai $E_{b} / N_{o}=5 \mathrm{~dB}$, sensitivitas $\mathrm{BS}$ yang didapat adalah sebesar $-119,42 \mathrm{dBm}$, nilai $E_{b} / N_{o}=6 \mathrm{~dB}$, sensitivitas $\mathrm{BS}$ adalah sebesar $-118,42 \mathrm{dBm}$, sedangkan nilai $E_{b} / N_{o}=7$ $\mathrm{dB}$, sensitivitas BS sebesar $-117,42 \mathrm{dBm}$.

Semakin tinggi bit rate yang digunakan, maka Sensitivitas BS (level daya terima MS minimum yang diterima BS agar MS dapat melakukan akses pada sel tersebut), akan semakin kecil nilainya. Untuk nilai $E_{b} / N_{o}$ yang semakin besar maka nilai sensitivitas BS akan semakin kecil, atau dapat juga dikatakan bahwa sensitivitas BS akan semakin baik.

Kualitas sistem yang baik dapat dicapai pada saat nilai $E_{b} / N_{o}$ sebesar $7 \mathrm{~dB}$ dengan bit rate 14400 bps, karena dengan kecilnya sensitivitas BS, maka secara tidak langsung daya pancar yang dibutuhkan MS untuk melakukan akses juga rendah, sehingga kualitas sistem juga akan semakin 
baik. Jika sensitivitas BS makin besar maka daya pancar MS juga harus ditingkatkan agar MS dapat dikenali oleh BS dan mencapai $E_{b} / N_{o}$ yang telah ditetapkan sebesar $7 \mathrm{~dB}$ sehingga tidak terjadi drop call.

Daya pancar yang rendah akan menurunkan nilai $E_{b} / N_{o}$ yang dibutuhkan untuk mengatasi derau dan interferensi, ini menyebabkan MS masih dapat beroperasi pada jarak yang lebih jauh sehingga meningkatkan kemampuan pencakupan sel. Ini berarti pengurangan jumlah sel yang dibutuhkan untuk mencakup wilayah tertentu. Daya pancar yang rendah akan menurunkan nilai $E_{b} / N_{o} \quad j u g a$ akan menghemat biaya karena hanya membutuhkan daya pancar yang kecil.

Perubahan nilai sensitivitas BS akan mempengaruhi radius cakupan sel tunggal WCDMA. Radius cakupan untuk daerah suburban lebih besar daripada radius cakupan untuk daerah urban.

Faktor koreksi ukuran kota yang dipilih adalah pusat kota/large city/metropolitan $\quad(\mathrm{CM}=3), \quad$ maka perhitungan ini akan mempengaruhi $E_{b} / N_{o}$ terhadap radius cakupan untuk daerah urban dan suburban yang dapat dillihat pada Gambar 3 berikut ini:

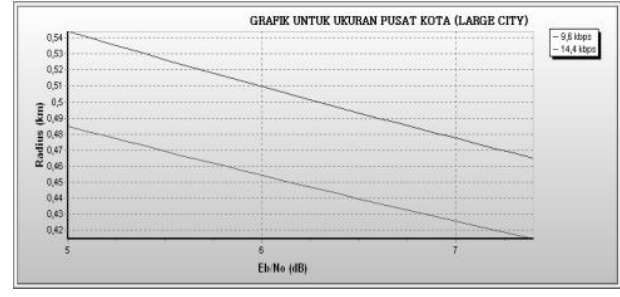

Gambar 3. Grafik Hubungan antara $\mathrm{Eb} / \mathrm{N}_{0}$ terhadap radius cakupan untuk daerah ber jenis urban di pusat kota dengan nilai $\mathrm{CM}=3$

Garis diatas pada grafik pada Gambar 3 menunjukkan hubungan menggunakan bit rate 9600 bps, dimana untuk nilai $E_{b} / N_{o}=5 \mathrm{~dB}$, radius cakupan = 0,544 km, sedangkan dibawah diatas pada grafik menggunakan bit rate 14400 bps, untuk nilai $E_{b} / N_{o}=5 \mathrm{~dB}$, radius cakupan $=$ $0,485 \mathrm{~km}$.

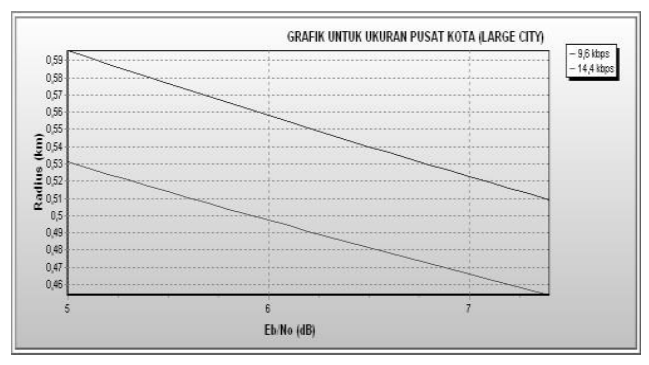

Gambar 4. Grafik Hubungan antara $\mathrm{Eb} / \mathrm{N}_{0}$ terhadap radius cakupan pada daerah suburban untuk pusat kota dengan $\mathrm{CM}=3$

Garis diatas pada grafik Gambar 4 menunjukkan hubungan antara $E_{b} / N_{o}$ terhadap radius cakupan pada daerah suburban untuk pusat kota yang menggunakan bit rate 9600 bps,dimana dengan nilai $E_{b} / N_{o}=5 \mathrm{~dB}$, radius cakupan = 0,596 km. Bitrate 14400 bps ditunjukkan oleh Garis dibawah pada grafik, dimana pada $E_{b} / N_{o}=5 \mathrm{~dB}$, radius cakupan $=0,531$ $\mathrm{km}$ 
Faktor koreksi ukuran kota yang dipilih adalah kota kecil-sedang $(\mathrm{CM}=0)$, maka mempengaruhi perubahan $E_{b} / N_{o}$ terhadap radius cakupan untuk daerah urban dan suburban dapat dilihat pada gambar berikut:

Pada Gambar 5 dan Gambar 6, garis diatas pada grafik menunjukkan hubungan antara $E_{b} / N_{o}$ terhadap radius cakupan menggunakan bit rate 9600 bps, dimana radius cakupan untuk daerah suburban lebih luas dibanding radius cakupan untuk daerah urban. Sedangkan garis dibawah pada grafik menunjukkan hubungan menggunakan 14400 bps, yang mempunyai radius cakupan lebih kecil.

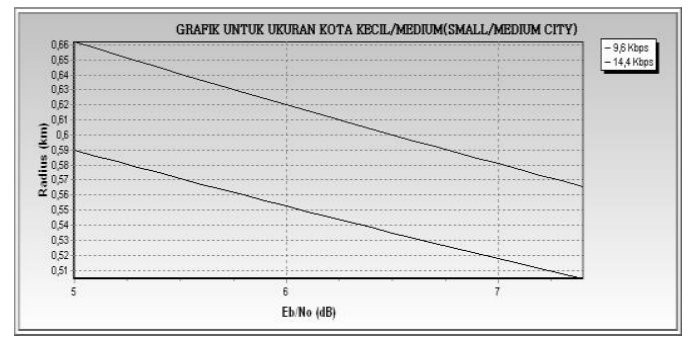

Gambar 6. Grafik Hubungan antara $E_{b} / N_{o}$ terhadap radius cakupan pada daerah urban untuk kota kecil-sedang dengan $\mathrm{CM}=0$

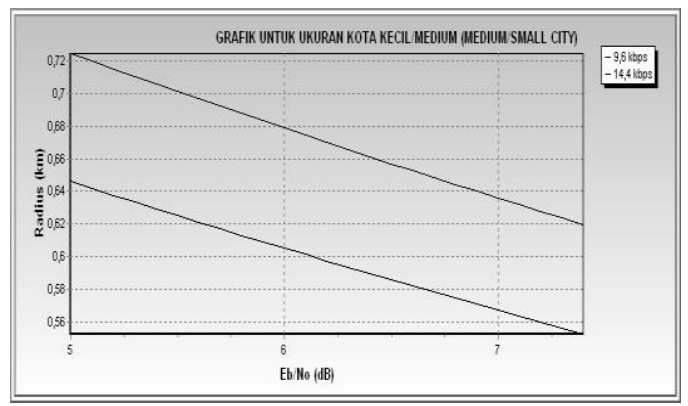

Gambar 6. Grafik Hubungan antara $\mathrm{Eb} / \mathrm{N}_{0}$ terhadap radius cakupan pada daerah suburban untuk kota kecil-sedang dengan $\mathrm{CM}=0$

\section{SIMPULAN}

Nilai $E_{b} / N_{o}$ dan bit rate yang digunakan semakin besar, maka mengakibatkan jumlah kanal yang ditawarkan akan semakin kecil, artinya beban trafik yang ditawarkan juga akan semakin kecil yang mengakibatkan kualitas sistem menjadi lebih baik. Semakin besar nilai $E_{b} / N_{o}$ dan bit rate yang digunakan juga akan mempengaruhi nilai sensitivitas BS menjadi semakin rendah, artinya daya pancar MS juga rendah untuk mempertahankan nilai $E_{b} / N_{o}$ agar tidak terjadi drop call,sehingga nilai MAPL dan PL juga akan semakin kecil yang dapat menyebabkan cakupan sel WCDMA semakin kecil.

\section{DAFTAR PUSTAKA}

[1] Abdur Rahman Haider,Abu Bakar Bhatti dan Ammar Ahmad Kirmani, "Radio Resource Management In $3 G$ UMTS Networks", Thesis Degree of Master of Science in Electrical Engineering Blekinge Institute of Technology, 2007

[2] Hubbul Walidany dan Dini Sulastiani,

"Studi Sistem Transmisi Pada Wideband Code Divison Multiple Access (WCDMA)", Jurnal Rekayasa Elektrika, Volume 4 No.2,2005

[3] Putu Dodi Irawan,Arfianto Fahmi dan Kris Sujatmoko ," Perencanaan Penempatan Base Station WCDMA Di Denpasar", Seminar Nasional Aplikasi Teknologi Informasi, Yogyakarta, Juni 2009 
[4] Sauter, Martin, "Beyond 3G - Bringing Networks,Terminals and the Web Together" , John Wiley \& Sons, United Kingdom, 2009.

[5] Rahmawati Amalia Kartini dan Ali Muayyadi, "The Performance Analysis of Combined MUD Decorelator and PIC in DS-CDMA", Paper Proceeding ICTel,pp 195-198, Bandung, 2009

[6] Rappaport, T S., " Wireless Communication Principle and Practice" Prentice Hall, Upper Saddle River New Jersey, 2002

[7] Mesa C. O., "Enhancement WCDMA Uplink Performance" University of Twente, Enschede The Netherland, Mei 2006 